Canadian Journal of Fisheries and Aquatic Sciences, 57(6): pp. 1190-1199 (2000).

http://pubs.nrc-cnrc.gc.ca/eng/home.html

http://article.pubs.nrc-

cnrc.gc.ca/RPAS/rpv?hm=HInit\&calyLang=eng\&journal=cjfas\&volume=57\&afpf=f00-

047.pdf

ISSN: $1205-7533$

DOI: 10.1139/cjfas-57-6-1190

(C) 2000 NRC Canada 


\title{
Assessing density-dependent establishment and dispersal: an example using caddisfly larvae
}

\author{
B.L. Kerans, Peter L. Chesson, and Roy A. Stein
}

\begin{abstract}
Density dependence in colonization is poorly understood. We studied colonization by a benthic, strean-dwelling caddisfly, Hydropscche slossonae, through experiments varying conspecific densities and environmental conditions. A model of larval acceptance or rejection of a locality (dispersal from the locality) was developed and fitted to the data to estimate the relative strengths of density-dependent and density-independent processes underlying dispersal. In spring and fall, we varied density, substrate size, and current velocity in laboratory experiments and varied density in field experiments. In the laboratory, dispersal of fifth instars was always density dependent, but the strength of density dependence was highest in spring when the proportion dispersing was lowest. Dispersal in field experiments was density dependent only in spring. Proportion dispersing was highest under low flow. The model fit to laboratory data suggested that stronger density dependence in spring occurred because of a reduction in density-independent dispersal stimuli with no change in density-dependent stimuli. In contrast, a change in density-dependent stimuli did appear to cause differences between the proportions dispersing under the two flow regimes. The model reveals the potential for density-independent dispersal stimuli to modify the strength of density dependence detectable at the population level.

Résumé : La dépendance à l'égard de la densité dans la colonisation est un phénomène mal connu. Nous avons étudié la colonisation par une phrygane, Hydropsyche slossonae, insecte benthique des milieux lotiques, grâce à des expériences faisant varier les densités conspécifiques et les conditions environnementales. Nous avons élaboré un modèle de l'acceptation ou du rejet par la larve d'une localité (dispersion à partir de la localité), et nous l'avons ajusté aux données pour estimer les forces relatives des processus dépendants et indépendants de la densité qui régissent la dispersion. Au printemps et à l'automne, nous avons fait varier en laboratoire la densité, la taille du substrat et la vitesse du courant, et nous avons fait varier la densité dans les expériences de terrain. En laboratoire, la dispersion des cinquièmes instars était toujours dépendante de la densité, mais la force de la dépendance à l'égard de la densité était au plus fort au printemps, quand la proportion qui se dispersait était la plus faible. Dans les expériences de terrain, e'est seulement au printemps que la dispersion était dépendante de la densité. La proportion qui se dispersait était la plus forte par faible ćcoulement. Le modèle ajusté aux données de laboratoire semble montrer que la plus forte dépendance à l'égard de la densité observée au printemps était liée à une réduction des stimuli de dispersion indépendants de la densité, sans changement dans les stimuli dépendants de la densité. Par contre, un changement dans les stimuli dépendants de la densité semblait bien causer des différences entre les proportions qui se dispersaient dans les deux régimes d'écoulement. Le modèle fait ressortir que les stimuli de la dispersion indépendante de la densité ont le potentiel de modifier la force de la dépendance à l'égard de la densité qui est détectable au niveau de la population.
\end{abstract}

[Traduit par la Rédaction]

\section{Introduction}

Processes involved in colonization by organisms as diverse as insects, fish, and small mammals may have major influences on local population densities (e.g., Kareiva 1987) and ultimately on the distribution and abundance of organisms on larger spatial scales. A key question in this regard is the extent to which establishment and dispersal of individu-

Received December 3, 1999. Accepted February 14, 2000. J 15463

B.L. Kerans, 'P.L. Chesson, ${ }^{2}$ and R.A. Stein. Department of Zoology, Ohio State University, Columbus, OH 43210 , U.S.A.

'Author to whom all correspondence should be sent at the following address: Department of Biology, Montana State University. Bozeman, MT 59717, U.S.A.

${ }^{2}$ Present address: Section of Evolution and Ecology, Storer Hall, University of California, Davis, CA 95616, U.S.A. als among habitat patches are influenced by local population density. Density-dependent establishment can restrict the range of local population densities (e.g., set ceilings for patch densities), and density-dependent dispersal may influence regional population regulation and persistence (Anholt 1995). In the common situation where dispersal is risky (e.g., Wilzbach et al. 1986), density-dependent dispersal can lead to density-dependent mortality or density-dependent loss from the system when dispersal processes are unidirectional, as is often the case in streams (Anholt 1995). In such cases, density-dependent dispersal can act as a densitydependent regulatory mechanism on a regional scale. Thus, colonization processes may play an important role in the regulation of population density on both small and large spatial scales.

Density-dependent colonization processes are not well understood. This is particularly true in streams despite the fact that invertebrate dispersal is a conspicuous process (e.g., Waters 1972). While there have been many attempts to ex- 
amine dispersal in stream insects, the relative importance of density-dependent versus density-independent dispersal remains ambiguous. Part of the ambiguity revolves around the lack of quantitative tools to directly compare the strength of density-dependent and density-independent processes underlying establishment and dispersal. We studied this question using larvae of the caddisfly Hydropsyche slossonae, a common inhabitant of stream riffles in the United States. Although hydropsychids have a sedentary lifestyle, constructing fixed retreats and filtering nets on rocks, they are often found drifting in the water column, reflecting dispersal activities (Walton 1980). Moreover, behavioral observations show that hydropyschids compete for retreat placement sites and defend their retreats from intrusion by conspecifics (Jansson and Vuoristo 1979; Matczak and Mackay 1990). Larvae also build retreats with more regular spacing patterns than expected by chance (Glass and Bovbjerg 1969; Kerans 1989). These results suggest that density dependence and interference are important for hydropyschid establishment and dispersal.

Colonization processes in hydropsychids and many other sedentary stream insect larvae can be usefully divided into the following four stages: (1) dispersal from a substrate by resident larvae (e.g., hydropsychids that have built retreats and capture nets), (2) drift in the water column (or less frequently crawling on substrate), (3) settling out of the water column onto a new substrate, and (4) acceptance of the new substrate and establishment and retreat construction, or rejection of the substrate and further dispersal. This model is a modification of one proposed by Minshall and Petersen (1985). One modification is the addition of the fourth stage, which is the focus of our empirical research. For hydropsychids, stages 1 and 4 are biologically distinct. Conditions promoting dispersal may differ between stages 1 and 4 because stage I larvae have already invested energy in retreat construction. Moreover, stage 4 commonly involves an active process of movement over the new substrate and provides a larva with the opportunity to assess the suitability of the microhabitat prior to retreat construction. Thus, this stage provides a strong opportunity for the abiotic and biotic conditions of the microhabitat to affect the organism's decision to stay or disperse. Abiotic conditions like current velocity and substrate size are often correlated with hydropsychid population densities (e.g., Statzner et. al 1988; Schlosser and Ebel 1989; Georgian and Thorp 1992); thus, they have the potential to influence colonization processes during stage 4 . Moreover, Matczak and Mackay (1990) showed that aggressive interactions that influence hydropsychid establishment and dispersal are confined to stage 4.

We studied the establishment and dispersal of $H$. slossonae through (i) development of a model and related statistical tests that allowed for straightforward tests of density-dependent and density-independent establishment and dispersal, (ii) empirical studies of how establishment and dispersal of $H$. slossonae changed temporally and were influenced by conspecific density and varying environmental conditions (current velocity and substrate size), and (iii) fitting the model to the data generated by the empirical studies to assess how the strengths of the underlying density-dependent and density-independent processes changed when establishment and dispersal varied.

\section{Density dependence and the establishment and dispersal model}

If the probability that an individual expresses a particular behavior is not related to the density of other individuals in the population, then that behavior can be considered density independent. In practice, probabilities are estimated as proportions of individuals in test groups that express a particular behavior, such as dispersal. Density independence is assumed to occur when the proportion exhibiting the behavior does not vary with the density of individuals. If the proportion varies with density, then density dependence occurs.

Typically, in studies of colonization of stream insects, density-dependent dispersal is empirically tested using one of two statistical methods. The first, and most direct, test uses the general linear model (analysis of variance (ANOVA)) to determine whether the proportion dispersing varies among densities (Walton et al. 1977; Wiley 1981). If significant variation is found, then density dependence is concluded. Patterns in the proportion dispersing are elucidated using pairwise comparisons among treatment means; typically, the proportion dispersing increases with increasing density. The second method regresses the number of individuals dispersing against density (Hildebrand 1974). This method relies on the relationships among proportion dispersing, numbers of individuals dispersing, and density. Theoretically, this method can detect density dependence and can provide more information than ANOVA. If the proportion dispersing increases with density (is density dependent), then the number of individuals dispersing plotted against density will exhibit a curvilinear relationship. If the proportion dispersing is constant across densities (is density independent), then the number of individuals dispersing will exhibit a linear relationship when plotted against density with the intercept through the origin. Thus, this technique relies on fitting curves of different shapes to graphs of number dispersing against density to determine if a density-dependent curve provides a better fit than a straight line through the origin. Often, this technique does not provide a clear test of density dependence because it is difficult to statistically distinguish between curvilinear and linear regressions.

We develop a model that is based on biological features underlying the phenomena of establishment and dispersal. In this case, we use the model in concert with ANOVAs to examine the strengths of density-independent and densitydependent processes underlying density dependence in the proportion dispersing. We envision these processes as densitydependent and density-independent stimuli experienced by individuals. Our model provides several benefits over traditional approaches used to assess density-dependent dispersal in stream insects. First, the model is a general one allowing for both density-dependent and density-independent stimuli, with density dependence occurring as a special case. Second, our model allows for direct comparisons of the strengths of density-dependent and density-independent processes underlying establishment and dispersal. Third, the model has additional benefits to the interpretation of the results. In particular, it shows that density dependence at the population level can be much reduced without any change in the underlying density-dependent behavior of the organisms because other factors have overriding effects. 
Following the definition of density dependence, our model of establishment and dispersal (stage 4) is expressed in terms of the proportion of a population dispersing. The proportion remaining ( 1 minus the proportion dispersing) includes those larvae settling and establishing on the substrate. Consider an individual insect larva present on a particular substrate subject to particular biotic and abiotic conditions. We assume that it disperses from that substrate as the result of either a sufficient density-independent stimulus (di) or a sufficient density-dependent stimulus (dd) or both. Using standard probability formulas, this means

$$
\begin{aligned}
P[\text { disperse }] & =P[\mathrm{di} \text { or } \mathrm{dd}] \\
& =P[\mathrm{di}]+P[\mathrm{dd} \text { and no di }] \\
& =P[\mathrm{di}]+P[\mathrm{dd} \mid \text { no } \mathrm{di}](1-P[\mathrm{di}])
\end{aligned}
$$

The term $P[\mathrm{dd} \mid$ no di], a conditional probability, is the probability of receiving a sufficient density-dependent stimulus and dispersing, given that the individual did not receive a density-independent stimulus sufficient to cause dispersal. Note that this expression involves no assumptions beyond the existence of the two different types of stimuli. We use the conditional probability because we do not assume independence of the density-dependent and density-independent stimuli. There are two alternatives to eq. 1, viz $P$ [disperse] = $P[\mathrm{dd}]+P[\mathrm{di} \mid$ no $\mathrm{dd}](1-P[\mathrm{dd}])$ and $P[$ disperse $]=P[\mathrm{dd}]+$ $P[\mathrm{di}]-P[\mathrm{dd}$ and di $]$. All three equations are alternative, mathematically correct ways of relating dispersal to the underlying stimuli. If the stimuli are independent, then $P[\mathrm{dd} \mid$ no di $]=$ $P[\mathrm{dd}], P[\mathrm{di} \mid$ no $\mathrm{dd}]=P[\mathrm{di}]$, and $P[\mathrm{dd}$ and $\mathrm{di}]=P[\mathrm{dd}] P[\mathrm{di}]$, and all three equations reduce to the common form $P$ [disperse $]=P[\mathrm{dd}]+P[\mathrm{di}]-P[\mathrm{dd}] P[\mathrm{di}]$, and there is no reason for choosing one over another. However, when independence of density-dependent and density-independent stimuli is not assumed, eq. 1 has the advantage that density-dependent stimuli occur in just one term, and under the reasonable assumption that the strength of density-independent stimuli does not vary as a function of density, only one of the three terms in eq. I has to be expressed as a function of density, greatly simplifying model fitting and interpretation.

Equation 1 immediately reveals some important information. If the probability of a sufficient density-independent stimulus is high, then the additional effects that a densitydependent stimulus may have on dispersal are weak. There are two reasons for this. First, in eq. I, $P[\mathrm{dd} \mid$ no di $]$ accounts for density-dependent stimuli, but it is multiplied by (1 $P[$ di]), which will be small if the probability of a densityindependent stimulus is high. The effects on the dispersal probability of $P[\mathrm{dd} \mid$ no di] are therefore reduced if the probability of a sufficient density-independent stimulus is high. Second, as the dispersal probability must lie between $P$ [di] and 1 , if $P[\mathrm{di}]$ is high, the effect that density dependence can have on dispersal is restricted to a narrow range, regardless of how strong those density-dependent stimuli are.

Equation 1 represents the proportion dispersing in terms of specific behavioral components. To estimate these components from experimental data, some assumptions are necessary. Let the probability of receiving a sufficient density-independent stimulus be a constant, $b_{0}$. The probability of a sufficient density-dependent stimulus (given no di) is presumably a monotonically increasing function of density taking the value 0 at 0 density of conspecifics and leveling off at 1 as the density becomes very high (i.e., it is nonlinear). One such function is the following:

$$
P[\mathrm{dd} \mid \text { no di }]=1-\exp \left(-h_{1} X\right)
$$

where $b_{1}$ is a constant and $X$ is the initial density. The parameter $b_{1}$ gives the per unit effect of density on the probability of dispersing by a density-dependent stimulus, given no sufficient density-independent stimulus. We refer to it as the interference coefficient. A function with properties similar to those of eq. 2 is the rectangular hyperbola

$$
P[\mathrm{dd} \mid \text { no } \mathrm{di}]=b_{1} X /\left(1+b_{1} X\right) \text {. }
$$

With the precision of the data commonly available in the study of stream insects, there is little reason to choose between these different functions or between these and some other function with properties required to represent the density-dependent response. However, eq. 2 has the benefit of being interpreted in terms of a random encounter process, as follows. Suppose that (i) encounters with other larvae are random, (ii) density-dependent dispersal occurs solely as a result of an encounter above some threshold level, which may be specific to the individual, and (iii) such above-threshold encounters occur with a frequency proportional to initial density. Then the probability of not receiving a sufficient density-dependent stimulus is the zero term of the Poisson probability distribution (Hassell 1978) and can be written in the form $\exp \left(-b_{1} X\right)$. Equation 2 now follows directly. We emphasize, however, that there are many other ways in which a formula indistinguishable in practice from eq. 2 might arise, and its use to separate density-dependent and density-independent processes is in no way dependent on special conditions.

We can now put together the components of the model to get the proportion of larvae dispersing under experimental conditions. Recognizing that the theoretical mean of the proportion of larvae dispersing in an experiment is the probability of dispersing, we obtain the equation

$$
\begin{aligned}
& \text { Proportion dispersing }=b_{0}+\left(1-b_{0}\right) \\
&\left(1-\exp \left(-b_{1} X\right)\right)+\text { random error. }
\end{aligned}
$$

This equation provides a nonlinear regression equation that can be fitted to data, with the parameters $b_{0}$ and $b_{1}$ being measures, respectively, of the density-dependent and densityindependent processes underlying dispersal. The interference coefficient, $b_{1}$, measures directly the per capita rate at which individuals receive density-dependent dispersal stimuli, and therefore, $b_{1} X$ is the total rate that an individual experiences. The model highlights an important distinction between the intensity of the underlying interactions between individuals, as measured by the interference coefficient, $b_{b}$, and the strength of the relationship between the proportion dispersing and density. Figure 1 shows that holding $b_{1}$ constant (maintaining the level of interactions between individuals) and increasing $b_{0}$ weakens the relationship between the proportion dispersing and density, making density-dependent dispersal more difficult to detect. The parameter $b_{0}$ may be affected by abiotic conditions of the microhabitat on the substrate and can be expected to vary as such conditions change. The parameter $b_{1}$ could also vary with changes in 
Fig. 1. Mean proportion of hydropyschids dispersing as a function of density for different values of density-independent stimuli, $b_{0}$, but with a fixed value of the interference coefficient, $b_{1}$ (0.003). Relative change in the proportion dispersing across densities expresses the intensity of density-dependent dispersal. Note that as $b_{0}$ becomes large, the slope of the curve approaches zero and the strength of density dependence decreases.

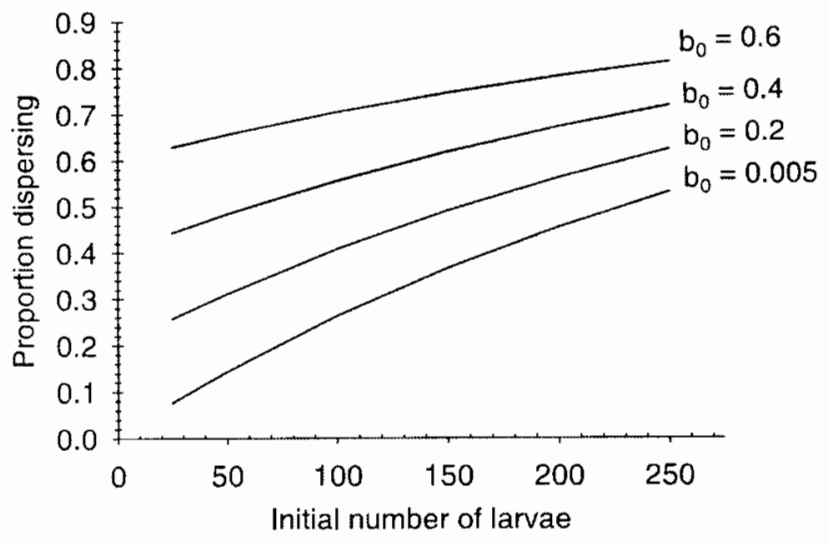

abiotic factors. In such cases, it measures the interaction between abiotic and biotic conditions.

We fitted the nonlinear regression to data generated in laboratory experiments examining establishment and dispersal of fourth- and fifth-instar $H$. slossonae larvae across various densities, environmental conditions (substrate sizes and flow regimes), and scasons. The model allowed us to evaluate how the density-dependent and density-independent establishment and dispersal processes changed under these varying conditions.

\section{Methods}

\section{Study site and organism}

Hydropsyche slossonae larvae were collected and field experiments were conducted in Macochee Creek, a third-order tributary of the Mad River flowing through primarily agricultural land in southern Logan County, Ohio. The creek is $15.5 \mathrm{~km}$ long and $6-15 \mathrm{~m}$ wide and is composed of a series of runs and pools interspersed with shallow $(<10 \mathrm{~cm})$ riffles. Hydropsyche slossonae is the most abundant hydropsychid within Macochee Creek, which is dominated by caddisfly and dipteran larvae (B.L. Kerans, unpublished data). Hydropsyche slossonae densities can be high (maximum of 57.1 larvae per $100 \mathrm{~cm}^{2}$ of rock surface area, $\bar{x}=6.1 \pm 0.9$, $n=135$, Kerans 1989; these and all other means are presented \pm 1 SE). Populations of H. slossonae are usually univoltine (Mackay 1986). Larvae in Macochee Creek overwinter as third, fourth, and fifth instars with pupation occurring in late spring.

\section{Laboratory experiments}

In laboratory experiments, we investigated how larval density, substrate size, and current velocity affected dispersal of fourth and fifth instars during two seasons (spring, fall winter). In May, the experimental design was two-way factorial manipulating three densities $(25,100$, and 200 larvae, which are equivalent to 5,20 , and 40 larvae $100 \mathrm{~cm}^{-2}$, respectively) and three substrate sizes (gravel, $1.25 \mathrm{~cm}$ in diameter; pebble, $5.00 \mathrm{~cm}$ in diameter; cobble, $8.00 \mathrm{~cm}$ in diameter). Only low-velocity conditions $\left(\approx 30 \mathrm{~cm} \cdot \mathrm{s}^{1}\right)$ and fifth instars were tested (Table 1) (fourth instars were uncommon in spring). Fuller and Mackay (1980) showed that velocities of $30 \mathrm{~cm} \cdot \mathrm{s}^{-1}$ are adequate for net construction.

Fall winter trials were conducted mostly between November and February, with some additional trials (seven of 64 total) conducted in early April. Fourth and fifth instars were tested in separate experiments. Experimental design was a three-way factorial manipulating three densities (as in spring), two substrate sizes (gravel, pebble), and two current velocities $\left(\approx 30\right.$ and $\approx 60 \mathrm{~cm} \cdot \mathrm{s}^{-1}$; Table 1). Three replicates were run for all treatment combinations except the fall-winter high-density trials using fourth instars, where only one replicate could be completed. Larval densities were within the range of those found in Macochee Creek (see Study site and organism section).

Experiments were conducted in four identical artificial stream tanks (length $117.7 \mathrm{~cm}$, width $15 \mathrm{~cm}$, depth $15.7 \mathrm{~cm}$ ). Water entered tanks through an approximately $7.6-\mathrm{cm}$ PVC pipe and passed through two mesh baffles to reduce turbulence. At the downstream end, water flowed through a $200-\mu \mathrm{m}-\mathrm{mesh}$ drift net and was collected in a large holding tank. Electric pumps recirculated the water, and temperature was regulated by a chilling unit in the holding tank. An experimental section $(15 \times 15 \mathrm{~cm})$ was positioned about $20 \mathrm{~cm}$ from the upstream end of each tank. Gravel $(<4 \mathrm{~mm}$ in diameter, the material used for larval retreat construction) and one size of test substrate were added to each upstream section. All substrates were periphyton-covered stones collected from Macochee Creek. Because hydropsychids inhabit and defend retreats attached to stone surfaces, the surface area available for establishment could influence dispersal (Reice 1980), and total surface area of stones was held constant $\left(\approx 500 \mathrm{~cm}^{2}\right)$. Surface area was estimated by individually wrapping all stones in aluminum foil and using standard regressions relating foil weight to surface area (Reice 1980).

Larvae were fed finely ground trout chow ad libitum and held at $12-15^{\circ} \mathrm{C}$ in well-aerated tanks for $\leq 3$ days before experiments. Larvae were added to the experimental section in still water. During the first hour, larvae were prevented from leaving the experimental section by plastic dividers placed slightly upstream and downstream of the section, and larvae that swam off stones were returned to the stones. After $\mathrm{l} h$, we removed the dividers and gradually increased flow over $5 \mathrm{~min}$. Drifting larvac were captured in the downstream net. No suspended food material was provided during a trial.

Trials began between 14:00 and 16:00 EST and ended the following morning between 9:00 and 10:00 EST, encompassing the peak drift period (Kerans 1996). We counted the number of larvae that had left the experimental section at the end of the trial. In addition, to check for the possibility of artifacts arising from the initial setup, we counted the number that had left $0.5 \mathrm{~h}$ after flow had been increased. Thus, we calculated two different dispersal proportions: $P_{\mathrm{l}}$, the total number of laryac that dispersed divided by initial number, and $P_{\mathrm{R}}$, the number of larvae dispersing after the first $0.5 \mathrm{~h}$ divided by those remaining in the upstream section after the first $0.5 \mathrm{~h}$.

\section{Field experiments}

The laboratory experiments allowed us to maintain controlled situations; however, we conducted field experiments to test for densitydependent establishment and dispersal under more natural conditions. In particular, these experiments tested for density dependence with natural levels of suspended organic particulates. Such particulates are difficult to maintain in laboratory trials but can influence hydropsychid dispersal, spacing of retreats, and distribution and abundance (Matczak and Mackay 1990; Richardson and Mackay 1991; Georgian and Thorp 1992).

We conducted two field experiments (spring, 4.7 June; fall, 3-17 December). Both current velocity $\left(\approx 30\right.$ and $\left.60 \mathrm{~cm} \cdot \mathrm{s}^{-1}\right)$ and density $\left(0,12\right.$, and 100 larvae tile ${ }^{-1}$, which are equivalent to $0,5.5$, and 45.5 larvae $100 \mathrm{~cm}^{-2}$, respectively) were investigated in a fac- 
Table 1. Physical conditions $(\bar{x} \pm 1$ SE) in laboratory and field experiments.

\begin{tabular}{|c|c|c|c|c|}
\hline & \multicolumn{2}{|l|}{ Flow $\left(\mathrm{cm} \cdot \mathrm{s}^{-1}\right)$} & \multirow[b]{2}{*}{ Depth $(\mathrm{cm})$} & \multirow[b]{2}{*}{ Water temperature $\left({ }^{\circ} \mathrm{C}\right.$} \\
\hline & Low & High & & \\
\hline \multicolumn{5}{|c|}{ Laboratory experiments } \\
\hline \multicolumn{5}{|c|}{ Spring } \\
\hline Instar V & $33.0 \pm 0.3(n=27)$ & & $8.3 \pm 0.2(n=27)$ & $14.1 \pm 0.1(n=27)$ \\
\hline \multicolumn{5}{|l|}{ Fall } \\
\hline Instar V & $32.3 \pm 0.5(n=18)$ & $59.2=0.4(n=18)$ & $8.2 \pm 0.2(n=36)$ & $13.0 \pm 0.1 \quad(n=36)$ \\
\hline Instar IV & $31.6 \pm 0.5(n=14)$ & $58.9 \pm 0.4(n=14)$ & $8.5 \pm 0.2(n=28)$ & $13.1 \pm 0.2(n=28)$ \\
\hline \multicolumn{5}{|c|}{ Field experiments } \\
\hline Spring & $31.0 \pm 3.0(n=5)$ & $67.5 \pm 7.6(n=6)$ & & $17.8=1.8(n=11)$ \\
\hline Fall & $36.8 \pm 4.1(n=12)$ & & & $5.0 \pm 1.0(n=12)$ \\
\hline
\end{tabular}

torial design in spring, but in fall, only the effects of density were studied. Densities were similar to those used in laboratory experiments. Larvae were marked by attaching metallic glitter to the thorax with Zapagap ${ }^{(\mathbb{R})}$ superglue, which has little or no effect on mortality or behavior (Kerans 1989).

Artificial substrates were made from plastic containers $(15 \times$ $15 \times 6 \mathrm{~cm})$ and slate tiles $(10 \times 10 \times 0.5 \mathrm{~cm}$, surface area $\left.220 \mathrm{~cm}^{2}\right)$. Tiles were attached to the inner surface $(15 \times 15 \times 1 \mathrm{~cm})$ of container tops. Gravel for retreat construction was placed between each tile and container top, producing a "sandwich." Bottoms of containers $(15 \times 15 \times 5 \mathrm{~cm})$ had $500-\mu \mathrm{m}$ mesh on two sides to allow water flow and formed covers to confine larvae initially.

Sandwiches were conditioned in stream riffles for 1 month. They were then cleaned of any colonizing organisms and debris and positioned in riffles such that tiles were flush with the stream bottom. A Marsh-McBirney current meter was used to choose appropriate flows. In a preliminary study, $H$. slossonae larvae readily colonized these sandwiches and built retreats.

At the beginning of an experiment, sandwiches were covered and marked larvae were added. After $1 \mathrm{~h}$, lids were removed and a downstream Surber sampler caught drifting larvae. Sandwiches remained in the riffle for 3 days in spring, whereas in fall, they were in place for 2 weeks (duration of the fall experiment was longer to increase colonization). To quantify mark loss during spring, 12 larvae were placed in two replicates in which covers were left in place. No marking control was done in the fall experiment because covers restricted flow and we expected survival to be low if larvae were confined by covers for 2 weeks. Mark retention was $100 \%$ in spring. At experiment's end, we determined the number of marked larvae that left and the number of unmarked $H$. slossonae and other hydropsychids that had colonized the sandwiches.

\section{Statistical analyses}

We assessed establishment and dispersal of hydropsychids using two sequential procedures. First, for both laboratory and field experiments, we used ANOVAs on the proportion dispersing. We then fit the model discussed above to portions of the laboratory data, specifically to main effects significant in ANOVAs, to gain the additional information available from this more quantitative approach. Thus, we assess the gains made from a model tailored to the system compared with a more traditional statistical approach.

Standard statistical analyses included separate, initial ANOVAs on $P_{1}$ and $P_{\mathrm{R}}$, including all interaction effects, except in the case of the fourth-instar experiment where the three-way interaction was omitted from the model because in some cells, only one trial was completed. Proportions were not transformed because examination of the residuals suggested that variances were homogeneous. Residuals from ANOVAs were plotted against other potential influencing variables (e.g., water depth, date of experiment). If a plot suggested a relationship, variables were included in an analysis of covariance (ANCOVA) and retained if significant $(p<0.05)$. We did not test for heterogeneity of regression slopes because significant covariates were balanced across all treatment combinations. Thus, any regression heterogeneity would not influence the outcome of treatments, and accounting for it would add unnecessary complexity to models (Smith 1957).

Where needed, comparisons of means, adjusted for any covariates, were done using population marginal means (i.e., SAS least squares means, Searle et al. 1980; SAS Institute Inc. 1985), with significance levels adjusted for the number of comparisons using the Bonferroni inequality. We also used one-way ANOVA, combining observations collected under similar laboratory conditions (all initial densities, gravel and pebble, and low flow), to compare dispersal between seasons.

In the field experiments, statistical analyses included separate ANOVAs on both $P_{1}$ and $P_{\mathrm{R}}$, as defined in the laboratory experiments, and on number of unmarked colonists. We also examined residuals as above. Proportions of marked larvae dispersing from the sandwiches did not require transformation; however, $(\ln +1)$ transformations were used on the number of unmarked colonists to stabilize variances.

In the second method of analyses of laboratory data, we fit the model to $P_{1}$ from the laboratory experiments (for main effects that were significant in ANOVAs) using SAS procedure NLIN and the Gauss-Newton iteration method (SAS Institute Inc. 1985). During the procedure, $b_{0}$ was constrained to be between 0 and 1 , whereas $b_{1}$ was $>0$. A multiple regression technique, using $\lambda$ and indicator variables for each treatment in a pair of comparisons (e.g., spring versus fall-winter), allowed simultaneous fitting of separate regressions for each treatment and comparison of the coefficients between regressions (Neter et al. 1983). Asymptotic maximum likelihood ratio tests were used to test whether coefficients differed signficantly from zero and differed between individual regressions. If $b_{0}$ differs from zero, then dispersal has a constant, densityindependent component. If $b_{1}$ differs from zero, then dispersal is density dependent. Significant differences between regressions in $b_{0}$ and $b_{1}$ values indicate that the treatments affect densityindependent and density-dependent processes. respectively. Both density-dependent and density-independent effects may be influenced by treatments; thus, comparisons of two regressions (e.g., between low and high flows) may yield significant differences between both $b_{0}$ values and $b_{1}$ values.

\section{Results}

\section{Laboratory experiments}

Few larvae left during the first $0.5 \mathrm{~h}$; consequently, $P_{!}$and $P_{\mathrm{R}}$ were similar in magnitude (always \pm 0.10 ). In most cases, treatments influenced $P_{1}$ and $P_{\mathrm{R}}$ similarly; therefore, we report results for $P_{\mathrm{R}}$ only when different from $P_{\mathrm{l}}$. 
During spring, dispersal of fifth instars was density dependent; $P_{1}$ increased with increasing initial density (Table 2; Fig. 2). We detected no difference in dispersal rates among substrate sizes, but $P_{\mathrm{I}}$ declined $1 \% \cdot$ day $^{-1}$ with trial date (Table 2). During fall and winter, $P_{1}$ increased with initial density and declined with increasing current velocity (Table 3; Fig. 3a). A significant three-way interaction (density, substrate, flow) probably occurred for two reasons. First. $P_{1}$ was similar across treatments at low density, but at high density, dispersal rates segregated by both current velocity and substrate size (Fig. $3 a$ ). Second, $P_{\mathrm{I}}$ in the pebble/ high current velocity treatment did not match the pattern in other treatments (Fig. 3a). The $P_{\mathrm{I}}$ declined $3 \% \cdot$ day $^{-1}$ for each day that larvae were held in the laboratory before a trial (Table 3). When the ANCOVA was run on $P_{\mathrm{R}}$, only initial density $\left(F_{2,23}=26.19, p<0.0001\right)$ and the covariate $\left(F_{1,23}=\right.$ $4.31, p=0.0492$ ) affected dispersal.

Dispersal of fourth instars was also density dependent (Table 3; Fig. 3b). Overall, fewer larvae dispersed from gravel than pebble; however, the proportion dispersing exhibited considerable variation between flows and substrate sizes. As with fifth instars, $P_{1}$ declined with increasing current velocity (Fig. $3 b$ ), although the response was marginally nonsignificant $(p=0.0565$; Table 3$)$. The $P_{1}$ declined $7 \% \cdot$ day $^{1}$ for each day that larvae were held in the laboratory before a trial (Table 3). When ANCOVA was run on $P_{\mathrm{R}}$, only substrate size $\left(F_{1,17}=1.75, p<0.0449\right)$ and the covariate $\left(F_{1.17}=8.64, p<0.0092\right)$ influenced dispersal.

Under similar conditions (gravel and pebble substrates and low current velocity), $P_{1}$ differed between instars and seasons (one-way ANOVA, $F_{2,47}=15.05, p<0.0001$ ). In spring, fifth instars had lower dispersal rates than either fourth or fifth instars in fall-winter $(p<0.0002$ and 0.0001 , respectively), whereas in fall-winter, dispersal rates of fourth and fifth instars did not differ $(p>0.46$; compare solid and open bars in Figs. 2 and 3 ).

In both spring and fall-winter experiments, most larvae remaining in the upstream subsection had constructed retreats. Mean proportion constructing retreats was high for fifth instars (spring, $0.83 \pm 0.02, n=27$; fall-winter, $0.88 \pm$ $0.02, n=36)$ and slightly lower for fourth instars $(0.69 \pm 0.03$, $n=28$ ).

\section{Field experiments}

The spring field experiment supported laboratory results. The $P_{I}$ was larger when initial density was high than when it was low $(0.425 \pm 0.073$ and $0.125 \pm 0.06$, respectively; two-way ANOVA, $F_{1,3}=10.12, p=0.05$ ). We detected no difference in dispersal under different current velocities $\left(F_{1,3}=1.28, p=0.3403\right)$, nor was the interaction between current velocity and density significant $\left(F_{1,3}=0.06, p=\right.$ $0.8205)$. The $P_{1}$ was higher in fall than in spring but density independent (low density, $0.670 \pm 0.076$; high density, 0.650 \pm 0.055 ; one-way ANOVA, $F_{1,6}=0.04, p=0.8447$ ). In both experiments, results for $P_{1}$ and $P_{\mathrm{R}}$ were similar.

Number of unmarked $H$. slossonae and total number of hydropsychids colonizing tiles were low in both spring ( $H$. slossonae, $\bar{x}=0.73 \pm 0.30 ;$ hydropsychids, $\bar{x}=2.0 \pm$ $0.54 ; n=11$ ) and fall (H. slossonae, $\bar{x}=1.25 \pm 0.40$; hydropsychids, $\bar{x}=3.67 \pm 0.80: n=12$ ). We detected no difference in the number of unmarked $H$. slossonae colonists or
Table 2. ANCOVA for $P_{1}$, number of larvae dispersing divided by initital number of fifth-instar $H$. slossonae in spring laboratory experiments.

\begin{tabular}{lrlrll}
\hline Source of variation & $\mathrm{df}$ & MS & \multicolumn{1}{l}{$F$} & \multicolumn{1}{l}{$p$} \\
\hline Initial number & 2 & 0.2783 & & 71.42 & 0.0001 \\
Substrate size & 2 & 0.0002 & & 0.05 & 0.9511 \\
Substrate size $\times$ initial number & 4 & 0.0009 & 0.23 & 0.9195 \\
Date of trial (slope $\ldots . .0107)^{a}$ & 1 & 0.0330 & 8.47 & 0.0097 \\
Error & 17 & 0.0039 & & \\
\hline
\end{tabular}

${ }^{\circ}$ Date of each trial.

Fig. 2. Means, adjusted for the covariate (date), from the ANCOVA on $P_{1}$, the number of fifth-instar $H$. slossonae dispersing divided by initial number, for each substrate size at each initial number in the spring laboratory experiment. Open bars, gravel; solid bars, pebble; hatched bars, cobble. Lcast-squares pairwise comparisons of mean $P_{1}$ s indicated differences among all initial densities (all $p$ values $<0.0001$ ). Error bars represent \pm 1 SE.

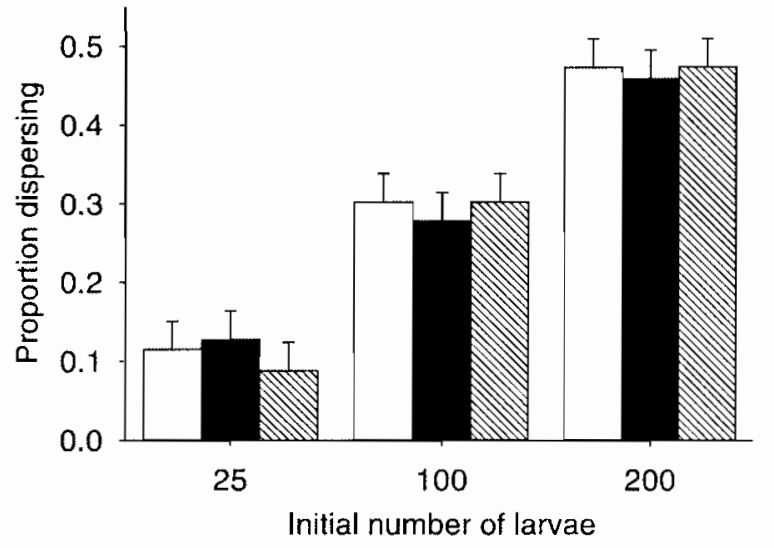

hydropsychid colonists between densities, current velocities, and their interaction in spring or among densities in fall (all $p$ values in ANOVAs $>0.05$ ).

\section{Model application}

The nonlinear regressions provided a good fit in both the fifth instar'season $\left(R^{2}=0.983, F_{4,32}=457.98, p<0.001\right)$ and fifth instar/current velocity comparisons $\left(R^{2}=0.989\right.$, $\left.F_{4,32}=696.53, p<0.001\right)$. In all regressions, $b_{0}$ and $b_{1}>0$; therefore, both density-dependent and density-independent processes contributed to dispersal (Table 4). However, reduction in dispersal of fifth instars from fall-winter to spring was related to a low $b_{0}$ (probability of sufficient densityindependent stimulus) in spring rather than to differences in intraspecific interactions (about $80 \%$ reduction in $b_{0}$; Table 4). Conversely, reduced dispersal under high-flow conditions resulted from a lowered interference coefficient, $b_{1}$ (38\% decrease in $b_{1}$; Table 4 ), which is interpreted in the model as a lower per capita rate of density-dependent stimuli, given no sufficient density-independent stimuli, thus suggesting a change in the underlying intensity of interactions between individuals at any given larval density. Although the nonlinear regressions provided a good fit to the data on fourth instars $\left(R^{2}=0.924, F_{4,28}=72.47, p<0.001\right)$, 
Table 3. ANCOVAs for $P_{1}$, number of larvae dispersing divided by initial number of fourth- and fifth-instar $H$. slossonae in fall winter laboratory experiments.

\begin{tabular}{|c|c|c|c|c|c|c|c|c|}
\hline \multirow[b]{2}{*}{ Source of variation } & \multicolumn{4}{|c|}{ Fifth instars } & \multicolumn{4}{|c|}{ Fourth instars } \\
\hline & $\mathrm{df}$ & MS & $F$ & $p$ & df & MS & $F$ & $p$ \\
\hline Initial number & 2 & 0.1474 & 57.61 & 0.0001 & 2 & 0.0500 & 3.99 & 0.0380 \\
\hline Current velocity & 1 & 0.0256 & 10.01 & 0.0043 & 1 & 0.0525 & 4.19 & 0.0565 \\
\hline Substrate size & 1 & 0.0006 & 0.24 & 0.6258 & 1 & 0.0877 & 6.99 & 0.0171 \\
\hline Substrate size $\times$ current velocity & 1 & 0.0075 & 2.94 & 0.1000 & 1 & 0.0158 & 1.26 & 0.2772 \\
\hline Current velocity $\times$ initial number & 2 & 0.0052 & 2.03 & 0.1538 & 2 & 0.0060 & 0.47 & 0.6312 \\
\hline Substrate size $\times$ initial number & 2 & 0.0032 & 1.24 & 0.3077 & 2 & 0.0268 & 2.13 & 0.1490 \\
\hline Substrate size $\times$ current velocity $\times$ initial number & 2 & 0.0104 & 4.04 & 0.0313 & & & & \\
\hline $\begin{array}{l}\text { Days in laboratory (slope }-0.0254 \text { fifth instars, } \\
-0.0715 \text { fourth instars) }\end{array}$ & 1 & 0.0155 & 6.06 & 0.0217 & 1 & 0.0861 & 6.87 & 0.0179 \\
\hline Error & 23 & 0.0026 & & & 17 & 0.0125 & & \\
\hline
\end{tabular}

"Number of days that larvac were held in the laboratory before a trial.

Fig. 3. Means, adjusted for the covariate (days in the laboratory), from the ANCOVA on $P_{1}$, the number of larvae dispersing divided by initial number of $(a)$ fifth- and $(b)$ fourth-instar $H$. slossonae in fall-winter laboratory experiments. Open bars, low flow/gravel; solid bars, low flow/pebble: hatched bars, high flow/gravel; cross-hatched bars, high flow/pebble. For fifth instars, least-squares pairwise comparisons of mean $P_{1} \mathrm{~s}$ revealed significant differences among the three densities $(p<0.017$, chosen by the Bonferroni inequality). Although there was an overall effect of density for fourth instars, pairwise comparisons by least-squares means did not detect specific differences $(p>0.017$, chosen by the Bonferroni inequality). Error bars represent $\pm I S E$.

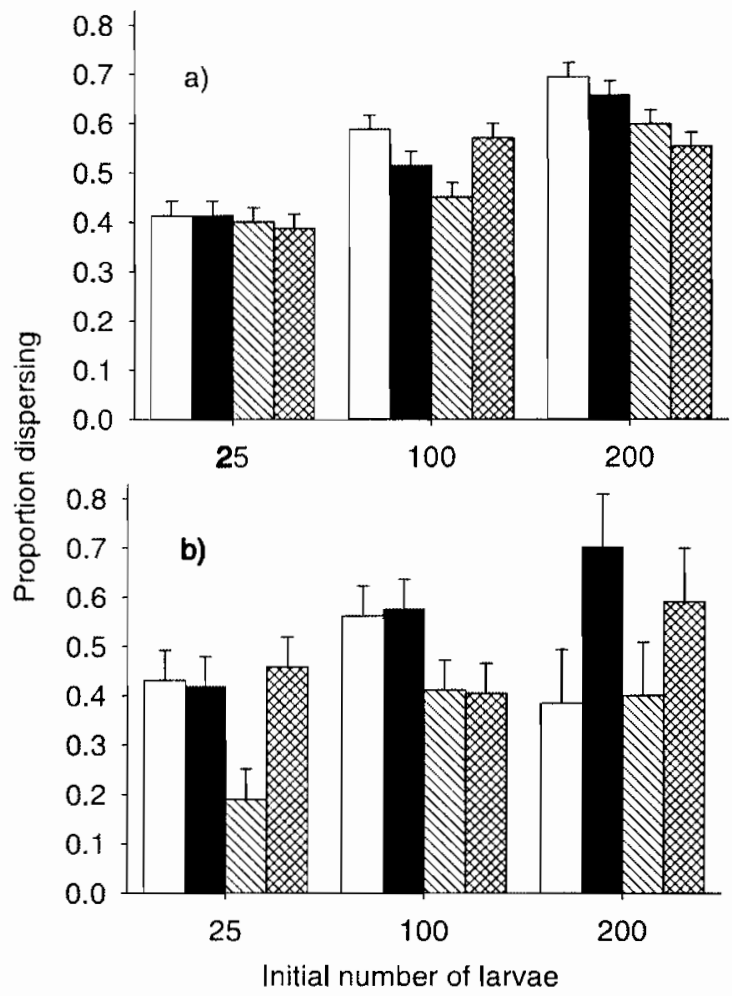

we were unable to determine whether the differences in dispersal across substrate sizes detected in the ANCOVA were due to density-dependent or density-independent stimuli (Table 4).

\section{Discussion}

Across season and microhabitat, establishment and dispersal of fifth-instar $H$. slossonae larvae were shown to be density dependent in the laboratory using ANOVAs. Field experiments yielded results similar to those in spring when dispersal rates were low but strongly density dependent (in laboratory and field experiments, dispersal tripled from low to high density). Conversely, in fall, dispersal rates were high and density independent in Macochee Creek and weakly density dependent in the laboratory (dispersal rate increased only $50 \%$ from low to high density). Fourth-instar dispersal was density dependent during the initial $0.5 \mathrm{~h}$ of trials but subsequently became density independent.

Using the model revealed more quantitative information about the relationship between individual dispersal behavior and density-dependent dispersal. In particular, density dependence in the probability of dispersal may not be proportional to the level of intraspecific interference occurring among individuals. Indeed, expressing the probability of dispersal as the joint outcome of density-dependent and densityindependent stimuli (eq. 1) shows that such proportionality would not ordinarily be expected unless no densityindependent stimuli were present. Equation 1, which involves no assumptions beyond the existence of the two types of stimuli, shows that the effects of density-dependent and density-independent stimuli are necessarily interactive. The quantity $P[\mathrm{dd} \mid \mathrm{di}]$ in eq. 1 can be regarded as measuring the strength of density-dependent stimuli and therefore quantifies the strength of interactions between larvae. However, the effect of $P[\mathrm{dd} \mid \mathrm{di}]$ on the probability of dispersal is equal to the product of $P[\mathrm{dd} \mid \mathrm{di}]$ and the probability of no sufficient density-independent stimulus. Thus, the effects that densitydependent stimuli have on dispersal are reduced by densityindependent stimuli. Put another way, if a high proportion of larvae would leave anyway as a result of densityindependent stimuli, there is little additional effect that density-dependent stimuli can have.

These interactive effects of density-dependent and densityindependent stimuli on dispersal clarify the results of the ex- 
Table 4. Nonlinear regression coefficients ( \pm asympotic SEs) for comparing hypothesized behavioral bases of differences among $P_{1} s$, number dispersing divided by initial number of $H$. slossonae larvae.

\begin{tabular}{lll}
\hline & \multicolumn{1}{l}{ Coefficient } & $b_{1}$ \\
\hline $\begin{array}{l}\text { Fifth instar, season } \\
\quad b_{0}\end{array}$ & $0.0029(0.0003)^{* * *}$ \\
$\quad \begin{array}{l}\text { Spring } \\
\text { Fall }\end{array}$ & $0.0621(0.0314)^{* * *}$ & $0.0034(0.0005)^{* * *}$ \\
Fifth instar, current velocity & $0.3634(0.0323)^{* * *}$ & $0.0034(0.0005)^{* * *}$ \\
$\quad$ Low & $0.3634(0.0323)^{* * *}$ & $0.0021(0.0004)^{* * *}$ \\
$\quad$ High & $0.3717(0.0282)^{* * *}$ & $0.0021(0.0012)^{* *}$ \\
Fourth instar, substrate size & $0.2969(0.0714)^{* * *}$ & $0.0022(0.0014)^{*}$ \\
$\quad$ Gravel & $0.3902(0.0716)^{* * *}$ & \\
$\quad$ Pebble &
\end{tabular}

Note: Regressions were for scason, current velocity, and substrate size effects shown to be significantly different in ANOVA (ANCOVA). Asterisks indicate asymptotic $t$ test $H_{0} ; b_{0}, b_{1}>0 ;{ }^{* * *} p<0.0005,{ }^{* *} p<$ $0.05,{ }^{*} p<0.1$. Vertical lines connect coefficients that did nol differ $(p>0.05)$ as determined by nonlinear regressions with indicator variables.

"Fall fifth instar and low current velocity are the same regressions.

periments. For instance, the fact that density dependence is weaker in fall than in spring experiments does not necessarily mean that individual larvae have fewer encounters in fall than in spring at the same larval densities; the similar interference coefficients $\left(b_{1}\right)$ in the spring and fall suggest that negative interactions between individuals are similar in these two seasons. Here, the reduction in the strength of density dependence simply reflects much greater densityindependent dispersal in fall than in spring, which weakens the relationship between the proportion dispersing and density (Fig. 1).

The reduction in the propensity of an individual to disperse in spring may be related to features of the life cycle or the environment. For example, fifth instars may become less apt to disperse, reducing density-independent movement as they approach pupation in spring. In spring, fifth instars are heaviest and drift infrequently (Kerans 1992). In the laboratory, temperatures and flows were kept the same in the different seasons, and so, those factors cannot explain the differences in dispersal behavior. Morever, the similarities of results of our laboratory experiments (where no food was provided) and ficld experiments suggest that variation in food quality or quantity between seasons does not explain differences in dispersal.

The ANOVAs showed that both fourth and fifth instars dispersed less frequently when flows were high. Results of the model suggest that these differences in dispersal between flow regimes resulted from an alteration in the interference coefficient (significant differences between $b_{1}$ but not $b_{0}$ between regressions) rather than any direct affect of the abiotic condition on the density-independent stimulus to leave. Because interactions between organisms are often based on direct encounters, any environmental factor that influences the frequency, intensity, or outcome of an encounter has the potential to influence the outcome of the interaction and thus the interference coefficient. Such effects are common. For example, Fletcher and Underwood (1987) have shown that physical features of the substrate influence competition between two limpet species. Moreover, microhabitat factors, such as the presence of refuges, influence interactions between many types of predators and their prey (e.g., Stein 1977; Sih 1987). Trichopteran fighting success, locomotory activity, and net building are influenced by flow (for a review, see Statzner et al. 1988). Reduction in encounters with other larvae under high flows could result because larvae are less active under high flows. Alternatively, Fuller and Mackay (1980) have shown that $H$. slossonae constructs more capture nets under high flows. In this case, larvae would spend less time actively searching for suitable sites and construct retreats sooner than under low-flow conditions. Involvement in retreat and net construction may reduce the number of encounters with other larvac. Moreover, under high flows, more larvae will invest energy in constructing retreats and nets than under low flow and may be less likely to leave after an aggressive encounter.

The behavior of larvae predicted by fitting the model to data from experiments conducted under low and high flow is also consistent with the theory that larvae exhibit densitydependent habitat rejection (i.e., habitat selection). Theories of density-dependent habitat selection assume that individuals select those habitats that convey the greatness fitness (e.g., Fretwell and Lucas 1970). In the simplest models, fitness is expected to be inversely related to population densities, and the distribution and abundance of individuals across habitats will reflect a trade-off between physical habitat quality and intraspecific density. Our high-flow regime may support higher densities than our low-flow regime because it provides a better quality habitat for hydropsychids. Hydropsychid densities often increase with increasing flow (Schlosser and Ebel 1989). Using simulations, Loudon and Alstad (1990) showed that particle capture rates for hydropsychid nets increase with flow, and Georgian and Thorp (1992) found that hydropsychids select high-flow regimes that deliver food at higher rates than low-flow regimes. Although little is known directly about habitat-related fitness of hydropsychids, Englund (1991) has shown that hydropsychids in the rear of larval aggregations experience lower flow and are smaller than those in the front of aggregations. The results from our model suggest that dispersal differences between flow regimes are related to an interaction between the quality of the habitat and interference.

Our results also have implications for field studies of drift of hydropsychids. The density-dependent establishment and dispersal found in our studies suggest that drift should be 
density dependent; however, most studies suggest that hydropsychid drift is density independent (Reisen and Prins 1972; Hildebrand 1974; Statzner et al. 1985). These studies were conducted on larger spatial scales than our experiments. The detection of density dependence on large spatial scales depends on the strength of density dependence on local scales, the variability of the response, and the strength of other factors influencing hydropsychid movement. Our results show that on local scales, strong, density-dependent dispersal is an intermittent process. For $H$. slossonae, densitydependent dispersal is probably most easily detected on large spatial scales in spring when the local densitydependent dispersal response is strong. In fall, weak density dependence combined with high variability on local scales (i.e., the patchy nature of stream benthos) may preclude detection of density dependence on larger spatial scales. When density dependence is weak on local scales, the influence of other environmental factors may make detection of density dependence difficult even on Jocal scales, as shown by our fall field experiments and implied by our model analysis. If strong density dependence is intermittent for other hydropsychids, then the lack of detection of density-dependent dispersal on large spatial scales could result because studies were conducted when density dependence was weak. Lack of detection of density dependence during a single time period does not mean that interference could not be strong at other times and important in population regulation. Intermittent density-dependent dispersal could, as discussed by Wiens (1977) for resource competition, cause "ecological crunch" periods that may influence populations long after competition can be detected.

For $H$. slossonae larvae, establishment and dispersal are influenced by microhabitat characteristics and local population density. Density-dependent dispersal probably plays a key role in local populations through density-dependent habitat selection. However, the effect of density dependence on dispersal varies across space and time. Because variability in density dependence at the population level may be caused by changes in individual behavior unrelated to density, densitydependent interactions among larvae, or both, there is no simple, direct relationship between strength of density dependence at the population level and the level of interference an individual experiences, unless other factors are controlled. Quantitative expression of the results in a nonlinear regression model was essential to understand such interactions in this study. By estimating the interference coefficient, $b_{1}$, we measured the strength of the underlying interference among larvae because the model factors out the effect of a density-independent stimulus, even when strong, to reveal the full potential of density-dependent stimuli. The model cannot compensate for reduced information on density dependence that exists naturally when there is a strong densityindependent effect, but it does correct for the bias in estimation of the density-dependent effects that would occur in a standard linear analysis of the problem.

\section{Acknowledgements}

Comments by J. Brawn, M. Butler, D. Culver, R. Fuller, J. Jannot, M. Mather, T. McMahon, and anonymous reviewers greatly improved earlier versions of this manuscript. We also would like to thank K. Gross, E. Marschall, G. Mittelbach, J. Reeve, A. Taylor, the Ohio State ECOLUNCH and EDIT groups, and individuals associated with the Aquatic Ecology Laboratory for many helpful discussions. We are especially grateful to D. Armstrong, P. Cunningham, C. Habicht, J. Kerans, S. Klosiewski, C. Knight, C. Mallison, J. Miner, D. Parrish, C. Price, S. Savage, J. Wahl, and F. Weng for help in the field and laboratory. C. Cowan helped with some figures. Special thanks go to B. Peckarsky and J. Karr, as the manuscript was revised while B.L.K. was a postdoctoral associate in their laboratories. Funds for this research were provided by National Science Foundation Dissertation Improvement Grant BSR 8701166, a Grant-in-Aid from Sigma Xi, an Alumni Research Award (Graduate School, Ohio State University), and the Department of Zoology and Aquatic Ecology Laboratory (Ohio State University).

\section{References}

Anholt, B.R. 1995. Density dependence resolves the stream drift paradox. Ecology, 76: 2235-2239.

Englund, G. 1991. Asymmetric resource competition in a filterfeeding stream insect (Hydropsvche siltalai: Trichoptera). Freshwater Biol. 26: 425-432.

Fletcher, W.J., and Underwood, A.J. 1987. Interspecific competition among subtidal limpets: effect of substratum heterogeneity. Ecology, 68: 387-400.

Fretwell, S.D., and Lucas, H.L., Jr. 1970. On territorial behavior and other factors influencing habitat distribution in birds. I. Theoretical development. Acta Biotheor. 19: 16-36.

Fuller, R.L., and Mackay, R.J. 1980. Field and laboratory studies of net-spinning activity by Hydropsyche larvae (Trichoptera: Hydropsychidae). Can. J. Zool. 58: 2006-2014.

Georgian, T., and Thorp, J.H. 1992. Effects of microhabitat selection on feeding rates of net-spinning caddisfly larvae. Ecology, 73: 229240.

Glass, L.W., and Bovbjerg, R.V. 1969. Density and dispersion in laboratory populations of caddisfly larvae (Chermatopsyche, Hydropsychidae), Ecology, 50: 1082-1084.

Hassell, M.P. 1978. The dynamics of arthropod predator prey systems. Princeton University Press, Princeton, N.J.

Hildebrand, S.G. 1974. The relation of drift to benthos density and food level in an artificial stream. Limnol. Oceanogr. 19: 951-957.

Jansson, A., and Vuoristo, T. 1979. Significance of stridulation in larval Hydropsychidae (Trichoptera). Behaviour, 71: 167-185.

Kareiva, P.1987. Habitat fragmentation and the stability of predator prey interactions. Nature (Lond.), 326: 388--390.

Kerans, B.L. 1989. Causes and consequences of density-dependent dispersal of the caddisfly Hydropsyche slessonae. Ph.D. dissertation, Ohio State University, Columbus, Ohio.

Kerans, B.L. 1992. Season and body size influence movement of hydrow psychid caddistly larvae. Can. J. Fish. Aquat. Sci. 49: $259-265$.

Kerans, B.L. 1996. The influence of periphyton and rock texture on the diel drift periodicity of a hydropsychid caddisfly. J. Freshwater Ecol. 11: 163-169.

Loudon, C., and Alstad. D.N. 1990. Theoretical mechanics of particle capture: predictions for hydropsychid caddisfly distributional ecology. Am. Nat. 135: 360-381.

Mackay, R.J. 1986. Life cycles of Hydropsyche riola, H. slossonae and Cheumatopsyche pettiti (Trichoptera: Hydropsychidae) in a spring-fed stream in Minnesota. Am. Midl. Nat. 115: 19-24. 
Matczak, T.Z., and Mackay, R.J. 1990. Territoriality in filter-feeding caddisfly larvae: laboratory experiments. J. North Am. Benthol. Soc. 9: 26-34.

Minshall, G.E., and Petersen, R.C., Jr. 1985. Towards a theory of macroinvertebrate community structure in stream ecosystems. Arch. Hydrobiol. 104: $49 \cdots 76$

Neter, J., Wasserman, W., and Kutner, M.H. 1983. Applied linear regression models. R.D. Irwin, lnc., Homewood, Ill.

Reice, S.R. 1980. The role of substratum in benthic macroinvertebrate microdistribution and litter decomposition in a woodland stream. Ecology, 61: 580-590.

Reisen, W.K., and Prins, R. 1972. Some ecological relationships of the invertebrate drift in Praters Creek, Pickens County, South Carolina. Ecology, 53: 876-884.

Richardson, J.S., and Mackay, R.J. 1991. Lake outlets and the distribution of filter feeders: an assessment of hypotheses. Oikos, 62: $370-380$.

SAS Institute Inc. 1985. SAS user's guide: statistics, version 5 edition. SAS Institute Inc., Cary, N.C.

Schlosser, I.J.. and Ebel, K.K. 1989. Effects of flow regime and cy. prinid predation on a headwater stream. Ecol. Monogr. 59:41 57.

Searle, S.R., Speed, F.M., and Milliken, G.A. 1980. Population marginal means in the linear model: an alternative to least squares means. Am. Stat. 34: $216 \cdots 221$.

Sih, A. 1987. Predators and prey life-styles: an evolutionary and ecological overview. In Predation direct and indirect impacts on aquatic communities. Edited bv W.C. Kerfoot and A. Sib. University Press of New England, Hanover, N.H. pp. $203 \cdots 224$.
Smith, H.F. 1957. Interpretation of adjusted treatment means and regressions in analysis of covariance. Biometrics, $13: 282 \cdots 308$.

Statzner, B., Elouard, J.-M., and Dejoux, C. 1985. Field experiments on the relationship between drift and benthic densities of aquatic insects in tropical streams (lvory Coast). II. Cheumatopsyche falcifera (Trichoptera: Hydropsychidae). J. Anim. Ecol. 55: 93 110.

Statzner, B., Gore, J.A., and Resh, V.H. 1988. Hydraulic stream ecology: observed patterns and potential applications. I. North Am. Benthol. Soc. 7: 307 360 .

Stein, R.A. 1977. Selective predation, optimal foraging, and the predator prey interaction between fish and crayfish. Ecology, 58: $1237-1253$.

Walton, O.E., Jr. 1980. Active entry of stream benthic macroinvertebrates into the water column. Hydrobiologia, 74: 129-139.

Walton, O.E., Jr., Reice, S.R., and Andrews, R.W. 1977. The effects of density, sediment particle size and velocity on drift of Acroneuria abnormis (Plecoptera). Oikos, 28: 291-298.

Waters, T.F. 1972. The drift of stream insects. Annu. Rev. Entomol. 17: 253 272.

Wiens, J.A. 1977. On competition and variable environments. Am. Sci. 65: $590-597$.

Wiley, M.J. 1981. Interacting influences of density and preference on the emigration rates of some lotic chironomid larvae (Diptera: Chironomidae). Ecology, 62: $426 \cdots 438$.

Wilzbach, M., Cummins, K.W., and Hall, J.D. 1986. Influence of habitat manipulations on interactions between cutthroat trout and invertebrate drift. Ecology, 67; 898-911. 